\title{
Marie-Laure Chaieb (dir.), Élites contestées et contestataires dans le monde biblique. Figures paradoxales
}

Introduction de Jean Riaud. Paris, Honoré Champion, 2012, 198 p.

\section{Daniel Vidal}

\section{OpenEdition \\ Journals}

Édition électronique

URL : http://journals.openedition.org/assr/24256

DOI : $10.4000 /$ assr.24256

ISSN : $1777-5825$

Éditeur

Éditions de l'EHESS

Édition imprimée

Date de publication : 30 décembre 2012

Pagination : 140

ISSN : 0335-5985

Référence électronique

Daniel Vidal, « Marie-Laure Chaieb (dir.), Élites contestées et contestataires dans le monde biblique. Figures paradoxales », Archives de sciences sociales des religions [En ligne], 160 | octobre-décembre 2012, mis en ligne le 11 mars 2013, consulté le 21 septembre 2020. URL : http:// journals.openedition.org/assr/24256; DOI : https://doi.org/10.4000/assr.24256

Ce document a été généré automatiquement le 21 septembre 2020.

(c) Archives de sciences sociales des religions 


\section{Marie-Laure Chaieb (dir.), Élites contestées et contestataires dans le monde biblique. Figures paradoxales}

Introduction de Jean Riaud. Paris, Honoré Champion, 2012, 198 p.

Daniel Vidal

\section{RÉFÉRENCE}

Marie-Laure Chaieb (dir.), Élites contestées et contestataires dans le monde biblique. Figures paradoxales, Introduction de Jean Riaud. Paris, Honoré Champion, 2012, 198 p. 
1 Si l'ouvrage permet de distinguer, au cœur des élites institutionnelles, culturelles ou charismatiques, du peuple juif tel que la Bible en livre la connaissance, des tensions, conflits, dissidences et transgressions, qui vont décider de son histoire propre, c'est parce qu'il s'appuie sur un modèle de lecture qui, sans rien ignorer de la fécondité d'une lecture "littérale et minimaliste", bouleverse radicalement des textes, mettant en intrigue chapitres et versets, entretissant des éléments disséminés d'une histoire pour en reconstruire en permanence la fragile unité. C'est à cette condition exacte, de lecture-relecture sans cesse, que les "figures paradoxales" de la Bible - contestataires/contestées apparaissent en toute leur singularité. D'un paradoxe, l'autre, en effet: il fallait

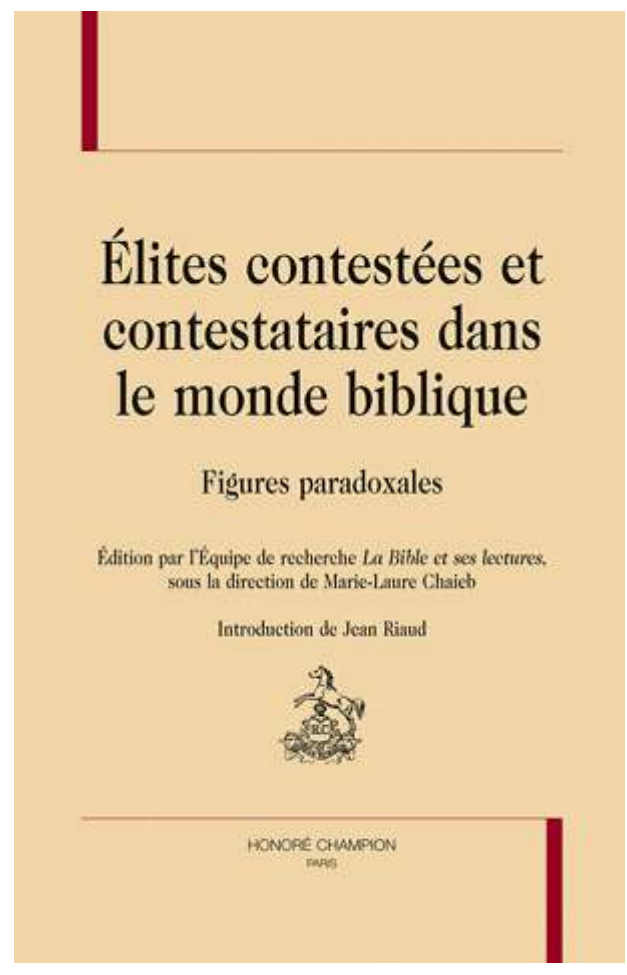
un coup de force dans le rapport du lecteur à l'Écriture, pour que re-naissent telles figures en leur engagement "historique» et leur capacité d'insoumission. À quoi s'est employée l'équipe de recherche "La Bible et ses lectures" (Département de recherches en Théologie et Sciences religieuses de l'Université Catholique de l'Ouest - Angers) - dont une première publication (Les élites dans le monde biblique, Champion, 2008) avait permis d'en identifier les critères culturels et sociaux. Place est faite, dans l'ouvrage présent, à leurs conflits internes, dont la résolution ouvre à chaque fois de nouvelles perspectives en l'histoire du peuple d'Israël.

2 Ainsi des crises de légitimité qui, sous la domination achéménide, traversent la communauté judéenne tout entière centrée sur l'espace du Temple, et qu'analyse Marianne Bertrand à partir de Nb 25. Le Temple, centre du «pouvoir» qui demeure, sous l'occupation, garant de la survie du peuple, et que se disputent laïcs et prêtres, pour le contrôle des fonctions cultuelles et des flux financiers qui les accompagnent. De l'ensemble des lignées sacerdotales, l'une l'emportera, la plus éloignée de la figure en partie "désacralisée " de Moïse, "le chef dépassé », et qui privilégiera, contre toute ouverture, le droit du sang. Sous la conduite de Pinhas le Nubien, l'identité juive va se refermer sur elle-même, et, par la fusion/ confusion de l'argument prophétique et de la fonction salvatrice, les interdits se multiplient contre les « étrangers ", les Madianites, avec lesquels Moïse avait tissé des liens sacrés. Rendues héréditaires, les prérogatives de la nouvelle légitimité sacerdotale annoncent la rétraction de la communauté sur elle-même, «chaque fois que l'identité juive est menacée de disparaitre au milieu des nations ».

Entre récit et cantique, travail de lecture et de relecture, appel du texte à l'hypertexte, de la narration à son noyau de "vérité", les "cas " Déborah et Yaël, en Jg 4-5, présentés par Josselin Roux, relèvent à l'évidence de ces figures paradoxales qui interdisent tout parcours convenu. Juge, prophétesse, Déborah transmet les ordres de 
Dieu, suscite un guerrier libérateur, et, inversant le statut social de la femme, s'affranchit de toute fonction subalterne. Transgressant, par sa capacité à reprendre en mains les destinées d'Israël, les « lois » de la cité, elle est emblème d'émancipation dans le texte ici et maintenant, et pour tout avenir. Yaël offre, dans la même configuration historique, un exemple analogue d'insoumission aux normes culturelles et à la damnation des lignées. Séductrice et héroïque, dissimulatrice et combattante, elle relève de la lignée quénite, et, s'enracinant en Israël en demeurant « fille de Caïn », par son action dans le vif de la guerre contre le royaume de Canaan, «elle brise la malédiction qui frappait » le fratricide. Au sein des élites du droit et de la guerre, ces femmes refondent l'histoire en rompant l'ordre de la tradition.

4 Tout chapitre de la Bible fonctionne comme un dispositif à plusieurs focales, « image lenticulaire" sollicitant une lecture démultipliée, seule capable de saisir ce "miroitement d'un versant à l'autre» du texte, du verset, du mot même en sa polysémie. Il est alors possible, avec Christophe Pichon, à partir de la matérialité des textes, de « lire » en Jonas et Jésus, des « réécritures » d'Ésaïe, dans leur solitude face au désert et à la mort. Désert venu de toute absence de dieu, abandon et délaissement quand tout vient à fin. Quel texte sert de "modèle » à l'autre? Peut-on penser en termes "figuristes" ou allégoriques le rapport des uns aux autres? Ne faut-il pas, comme y invite l'auteur, inverser l'argument, et poser au principe de leurs interrelations un même enjeu, capital, qui dit en tous textes le prophète acteur de sa propre mort, après qu'il ait porté contestation au cœur du monde? Une traversée intra-biblique est enrichissement des textes, et « plaisir de lecture ».

5 Ceci vaut aussi bien pour des énoncés extra-bibliques. Les Hymnes du Maître de justice, tels que rapportés dans les Manuscrits de la mer Morte, exigent, selon Valérie TripletHitoto, différents niveaux de lecture en raison de la pluralité des signes indiquant le lieu symbolique de l'autorité divine, y compris dans la dimension terrestre du « conseil divin». C'est précisément dans et par «la subtilité de la langue hébraïque » que le Maitre fonde son pouvoir dans la communauté essénienne de Qumrân. L'autorité politique, sacerdotale - ne peut s'entendre, et se définir, sans cette promotion du verbe en ses infinies déclinaisons. Elle peut en d'autres cas se fonder sur le rabattement habile d'un signe sur l'autre. Après la persécution de Dèce (249-250), les apostats qui voulurent revenir au christianisme, pouvaient soumettre leur demande à « l'élite des confesseurs et martyrs ", ou à " l'élite institutionnelle des prêtres ». À partir des Lettres de Cyprien de Carthage concernant les falsi, Marie-Laure Chaieb analyse le rapprochement progressif qu'effectue le rhéteur récemment converti, entre l'exemplarité des confesseurs de la foi, et l'exact respect de la disciplina que seule l'autorité épiscopale peut garantir en son principe. Sans ignorer que les martyrs en furent les gardiens rigoureux, privilège ne peut être accordé, étant donné les circonstances - et la menace de nouvelles persécutions (auxquelles Cyprien ne put échapper en 258) - qu'à l'élite de l'Église et ses conducteurs.

6 L'histoire se faufile entre les mailles du langage, le langage circule entre les contraintes d'histoire. Mais peut-on penser l'histoire «factuelle » sans le récit qui s'y énonce, et la narration sans l'historicité qui s'y accomplit? Tel est le débat ouvert par la mise à jour de ces contestations au sein des élites dans le monde biblique, quand, des textes à leurs lectures, chaque univers est à l'autre son miroir et sa chance. 